\title{
Glycerol Valorization: Dehydration to Acrolein Over Silica-Supported Niobia Catalysts
}

\author{
N. R. Shiju • D. R. Brown • K. Wilson • \\ G. Rothenberg
}

Published online: 11 June 2010

(C) The Author(s) 2010. This article is published with open access at Springerlink.com

\begin{abstract}
The catalytic dehydration of glycerol to acrolein is investigated over silica-supported niobia catalysts in a continuous fixed-bed gas-phase reactor. Various supported niobia catalysts are prepared and characterized using surface analysis and spectroscopic methods (XRD, UV-Vis, XPS, $\mathrm{N}_{2}$ adsorption), as well as with ammonia adsorption microcalorimetry. Good results are obtained with initial glycerol conversions of over $70 \%$ and with $50-70 \%$ selectivity to acrolein. We investigate the influence of changing the catalyst acid strength by varying the niobia content and catalyst calcination temperature. Glycerol conversion and acrolein selectivity depend on the surface acid strength. Catalyst deactivation by coking is also observed, but simple oxidative treatment in air restores the activity of the catalysts completely.
\end{abstract}

Keywords Glycerol - Niobia - Microcalorimetry · Heterogeneous catalyst $\cdot$ Renewable

N. R. Shiju ( $\bowtie) \cdot$ G. Rothenberg

Van't Hoff Institute for Molecular Sciences, University

of Amsterdam, Amsterdam, The Netherlands

e-mail: n.r.shiju@uva.nl

N. R. Shiju · D. R. Brown

Materials and Catalysis Research Centre, Department

of Chemical and Biological Sciences, University

of Huddersfield, Queensgate, Huddersfield HD1 3DH, UK

K. Wilson

Cardiff Catalysis Institute, School of Chemistry,

Cardiff University, Cardiff CF10 3AT, UK

\section{Introduction}

The search for catalytic processes targeting renewable raw materials for producing bulk chemicals is a 'hot topic'. Aiming at sustainable and 'green' processes, chemists must keep in mind the big picture, i.e. an overview of not only which raw materials are used, but where they're coming from and how do they relate to adjacent processes. Glycerol is a good example. It is a by-product of biodiesel synthesis from vegetable oil and animal fat (triglycerides), and though the amount of glycerol per tonne of biodiesel is small (ca. 1:10 ratio), the large tonnage of biodiesel for fuels means sufficient supply of glycerol for chemicals. In 2008, the total EU biodiesel production was 7.76 MMT [1]. This must increase considerably to meet the $4 \%$ target set by the EC [2]. Thus, the supply of glycerol in the coming decades is ensured, and with new heterogeneous catalytic processes for esterification and transesterification, the quality of this glycerol will only improve.

One important option for using this glycerol is converting it catalytically to acrolein via double-dehydration (Scheme 1). Such a process would offer a sustainable alternative to the present acrolein manufacturing technology that starts from petroleum-derived propylene. Acrolein is a key bulk chemical, produced on million-ton scale worldwide. It is used in making various products, including acrylic acid, acrylic esters, absorbent polymers and detergents [3].

To date, works involve dehydration of glycerol in either liquid or gas-phase using zeolites, oxides, sulfates, phosphates, heteropoly acids, and supported phosphoric acid [4-16]. Acrolein has also been prepared from glycerol using subcritical and supercritical water [17-19]. None of these processes are applied on a commercial scale. 
<smiles>OCC(O)CO</smiles>

glycerol

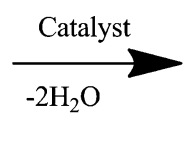

acrolein

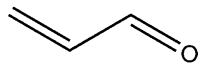

Scheme 1 Dehydration of glycerol to acrolein

Since glycerol is usually produced as a mixture with water, we wanted to use the glycerol-water mixture directly instead of pure glycerol for producing acrolein, requiring a catalyst with water-tolerant properties in addition to favourable acidic properties [20, 21]. Niobia was previously used as a solid acid catalyst in reactions that require water-tolerance [22, 23], so we selected supported niobia as the catalyst for the dehydration of glycerol to acrolein. As described herein, we have prepared various silica-supported niobia catalysts, characterised them and tested them in gas-phase glycerol dehydration.

\section{Experimental Section}

\subsection{Materials and Instrumentation}

Silica gel (Merck) was used as support (particle size $=0.063-0.200 \mathrm{~mm}$ ). Before impregnation, silica gel was calcined at $400{ }^{\circ} \mathrm{C}$. After calcination, the surface area was $480 \mathrm{~m}^{2} \mathrm{~g}^{-1}$ and pore volume was $0.79 \mathrm{~cm}^{3} \mathrm{~g}^{-1}$. Other chemicals were purchased from Aldrich and used as received. The niobia precursor used was ammonium niobate (V) oxalate hydrate, $\mathrm{C}_{4} \mathrm{H}_{4} \mathrm{NNbO}_{9} \cdot \mathrm{xH}_{2} \mathrm{O}(99.99 \%$, Aldrich). The gases were purchased from BOC. Powder $\mathrm{X}$-ray diffraction patterns were collected on a Bruker diffractometer using $\mathrm{Cu} K \alpha$ radiation. The $\mathrm{N}_{2}$ adsorptiondesorption isotherms were measured at $77 \mathrm{~K}$ on a Micromeritics ASAP-2000 after evacuation at $473 \mathrm{~K}$ for $5 \mathrm{~h}$. The surface areas and the average pore sizes were calculated by the BET and BJH methods, respectively. XPS measurements were performed using a Kratos AXIS HSi instrument equipped with a charge neutraliser and $\mathrm{Mg} \mathrm{K} \alpha \mathrm{X}$-ray source. Spectra were recorded at normal emission using an analyser pass energy of $40 \mathrm{eV}, \mathrm{X}$-ray power of $144 \mathrm{~W}$ and were energy referenced to the valence band and adventitious carbon. Survey scans were recorded at $160 \mathrm{eV}$ pass energy. Spectra were Shirley backgroundsubtracted across the energy region and deconvoluted using Casa XPS Version 2.3.15. The TG analysis was carried out using a thermal-analyzer (Mettler-Toledo) at a heating rate of $10{ }^{\circ} \mathrm{C} \mathrm{min}{ }^{-1}$. UV-Vis spectra were collected on PerkinElmer $\lambda 35$ spectrometer, using a labsphere reflectance spectroscopy accessory. The system used for ammonia adsorption flow calorimetry has been described previously $[24,25]$. Briefly, it is based on a Setaram 111 DSC with an automated gas flow and switching system, with a mass spectrometer (Hiden HPR20). After activation of the sample (20-30 mg) at $150{ }^{\circ} \mathrm{C}$ under a dried helium flow, $1 \mathrm{~mL}$ pulses of the probe gas (1\% ammonia in helium) at atmospheric pressure were injected at regular intervals into the carrier gas stream from a gas sampling valve. The net amount of ammonia irreversibly adsorbed from each pulse was determined by comparing the MS signal with that recorded through a control experiment with a blank sample tube. The net heat released by each pulse was calculated from the thermal DSC curve.

\subsection{Procedure for Catalyst Preparation}

All catalysts were prepared by impregnating the silica support with calculated amounts of an aqueous solution of ammonium niobium oxalate $\left[\mathrm{C}_{4} \mathrm{H}_{4} \mathrm{NNbO}_{9} \cdot \mathrm{xH}_{2} \mathrm{O}\right]$ to achieve the required loadings. The samples were then dried at $80{ }^{\circ} \mathrm{C}$ for $12 \mathrm{~h}$ and calcined at various temperatures in static air for $4 \mathrm{~h}$. The details of catalysts are provided in Table 1.

Table 1 Physico-chemical properties of silica-supported niobia samples

\begin{tabular}{llllllll}
\hline Entry & Catalyst & $\begin{array}{l}\text { Nominal } \\
\text { loading }(\mathrm{wt} \%)\end{array}$ & $\begin{array}{l}\text { Calcination } \\
\text { temperature }\left({ }^{\circ} \mathrm{C}\right)\end{array}$ & $\begin{array}{l}\text { BET surface } \\
\text { area }\left(\mathrm{m}^{2} \mathrm{~g}^{-1}\right)\end{array}$ & $\begin{array}{l}\text { Pore volume } \\
\left(\mathrm{cm}^{3} \mathrm{~g}^{-1}\right)\end{array}$ & $\begin{array}{l}\text { Average pore } \\
\text { diameter }\end{array}(\mathrm{nm})$ & $\begin{array}{l}\text { Average pore } \\
\text { diameter } \\
(\mathrm{nm})\end{array}$ \\
\hline $\mathbf{1}$ & $\mathrm{SiO}_{2}$ & 0 & 400 & 480 & 0.79 & - & - \\
$\mathbf{2}$ & $5 \mathrm{Nb}_{2} \mathrm{O}_{5}-\mathrm{SiO}_{2}-400$ & 5 & 400 & 471.5 & 0.66 & 5.2 & 5.1 \\
$\mathbf{3}$ & $10 \mathrm{Nb}_{2} \mathrm{O}_{5}-\mathrm{SiO}_{2}-400$ & 10 & 400 & 462.2 & 0.62 & 4.99 & 4.92 \\
$\mathbf{4}$ & $20 \mathrm{Nb}_{2} \mathrm{O}_{5}-\mathrm{SiO}_{2}-400$ & 20 & 400 & 459.9 & 0.61 & 4.88 & 4.82 \\
$\mathbf{5}$ & $40 \mathrm{Nb}_{2} \mathrm{O}_{5}-\mathrm{SiO}_{2}-400$ & 40 & 400 & 357.1 & 0.42 & 4.45 & 4.33 \\
$\mathbf{6}$ & $20 \mathrm{Nb}_{2} \mathrm{O}_{5}-\mathrm{SiO}_{2}-600$ & 20 & 600 & 434.5 & 0.55 & 4.84 & 4.75 \\
$\mathbf{7}$ & $20 \mathrm{Nb}_{2} \mathrm{O}_{5}-\mathrm{SiO}_{2}-800$ & 20 & 800 & 325.2 & 0.45 & 4.9 & 4.8 \\
$\mathbf{8}$ & $40 \mathrm{Nb}_{2} \mathrm{O}_{5}-\mathrm{SiO}_{2}-800$ & 40 & 800 & 258.8 & 0.34 & 4.7 & 4.6 \\
\hline
\end{tabular}

${ }^{\mathrm{a}}$ Calculated from $\mathrm{BJH}$ adsorption and ${ }^{\mathrm{b}}$ from $\mathrm{BJH}$ desorption 


\subsection{Procedure for Catalyst Testing}

The gas-phase dehydration reaction of glycerol to acrolein was carried out under atmospheric pressure in a vertical fixed-bed quartz reactor. A constant volume of catalyst was charged in the middle section of the reactor, with quartz wool packed in both ends. The reactor was also packed with ceramic beads above the catalyst bed in order to preheat and to vaporise the feed. The catalyst was then pretreated at $400{ }^{\circ} \mathrm{C}$ for $1 \mathrm{~h}$ in a flow of nitrogen $\left(60 \mathrm{~mL} \mathrm{~min}^{-1}\right)$. The temperature was then lowered to the required reaction temperature and the reaction feed, an aqueous solution containing $30 \mathrm{wt} \%$ glycerol, was fed into the reactor by a syringe pump. The reaction products were condensed in an ice-water trap and collected hourly for analysis on a Perkin Elmer Clarus 500 GC using a $50 \mathrm{~m}$ BP5 capillary column and an FID. The products collected during the first hour of the reaction were abandoned due to poor material balance.

\section{Results and Discussion}

\subsection{Catalyst Preparation and Characterization}

The catalysts were prepared by impregnating an aqueous solution of ammonium niobium oxalate onto silica. After the impregnation, the catalysts were dried and calcined in air. Table 1 shows the catalyst details and characterization data. Figure 1 shows the X-ray diffraction patterns of silica-supported niobia catalysts calcined at various temperatures. For samples with niobia loading lower than $40 \mathrm{wt} \%$, only a broad peak was observed. This was the case also for

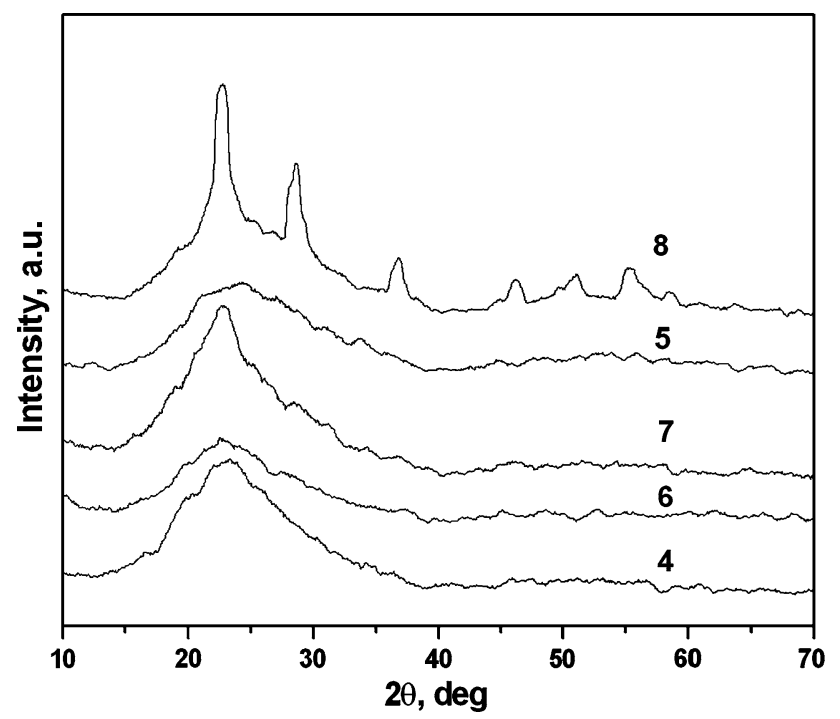

Fig. 1 X-ray diffraction patterns of some of the supported niobia catalysts. See Table 1 for the details of catalysts the sample containing $40 \%$ niobia, which was calcined at lower temperatures. This peak, centered at $22.6^{\circ}$, represents the orthorhombic (T) phase of niobium pentoxide [26]. For catalyst 8 (see Table 1 for details), more peaks were observed which can be assigned to characteristic reflections of $\mathrm{T}-\mathrm{Nb}_{2} \mathrm{O}_{5}$. Pure $\mathrm{Nb}_{2} \mathrm{O}_{5}$ undergoes crystallisation at lower temperatures, hence the XRD of the present samples show that higher temperatures are required for the crystallisation of niobium pentoxide when supported on silica. This indicates a high dispersion of niobia and stronger interaction between the supported niobia species and silica. Such interactions are frequently observed for supported metal oxides [27].

Table 1 gives the textural properties derived from nitrogen physisorption isotherms. Surface areas and pore volumes decreased with increasing the calcination temperature. The average pore diameter was $4.3-5.0 \mathrm{~nm}$, decreasing for higher niobia loadings. The thermogravimetric profiles of 20 and $40 \% \mathrm{Nb}_{2} \mathrm{O}_{5}$ samples showed that the decomposition of ammonium niobium oxalate occurred between 200 and $300{ }^{\circ} \mathrm{C}$, with increased mass losses at higher $\mathrm{Nb}$ content (Fig. 2).

The acidities were evaluated by ammonia adsorption microcalorimetry. In this method, the heat of $\mathrm{NH}_{3}$ adsorption is a direct measure of the total acid strength, and the surface coverage of $\mathrm{NH}_{3}$ gives an idea of the number of acid sites. The method, however, cannot distinguish Brønsted/Lewis sites. The initial heat of adsorption on silica support was $\sim 37 \mathrm{~kJ} \mathrm{~mol}^{-1}$ while the niobia containing samples showed a three-fold increase. This indicates the formation of new surface sites with higher acid strength. Since the $\mathrm{Nb}-\mathrm{O}$ bond has a higher ionic character, Lewis acid sites could be generated when $\mathrm{Nb}_{2} \mathrm{O}_{5}$ is incorporated into the silica matrix. The higher

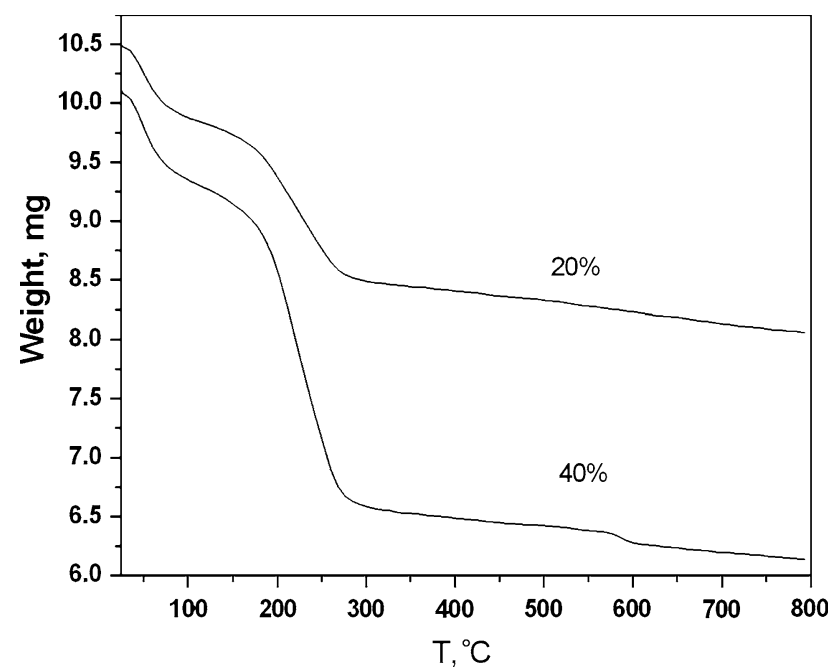

Fig. 2 TG analysis of silica-supported niobia catalysts with 20 and $40 \% \mathrm{Nb}_{2} \mathrm{O}_{5}$ loading 


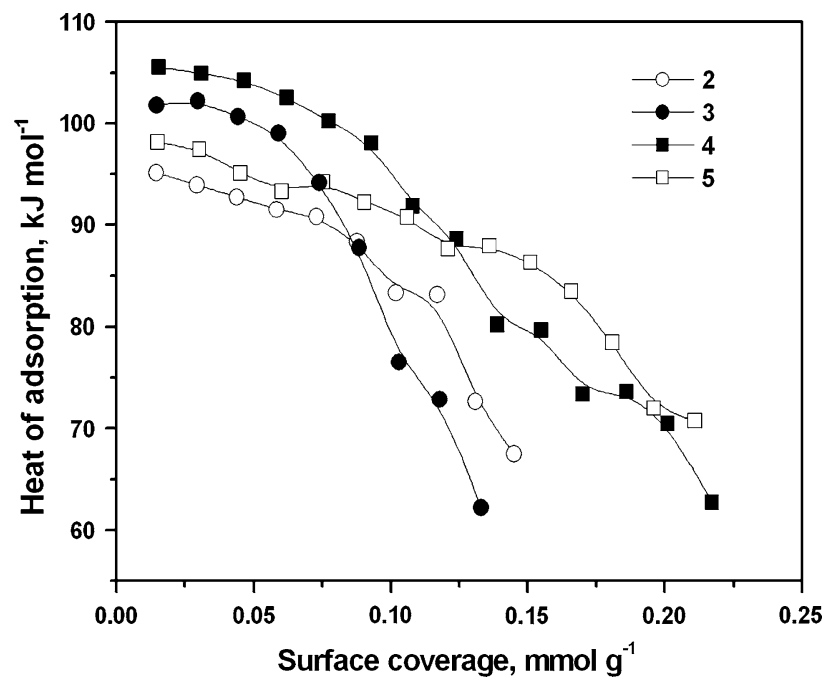

Fig. $3 \mathrm{NH}_{3}$ adsorption microcalorimetry data as a function of niobia loading. See Table 1 for catalyst details

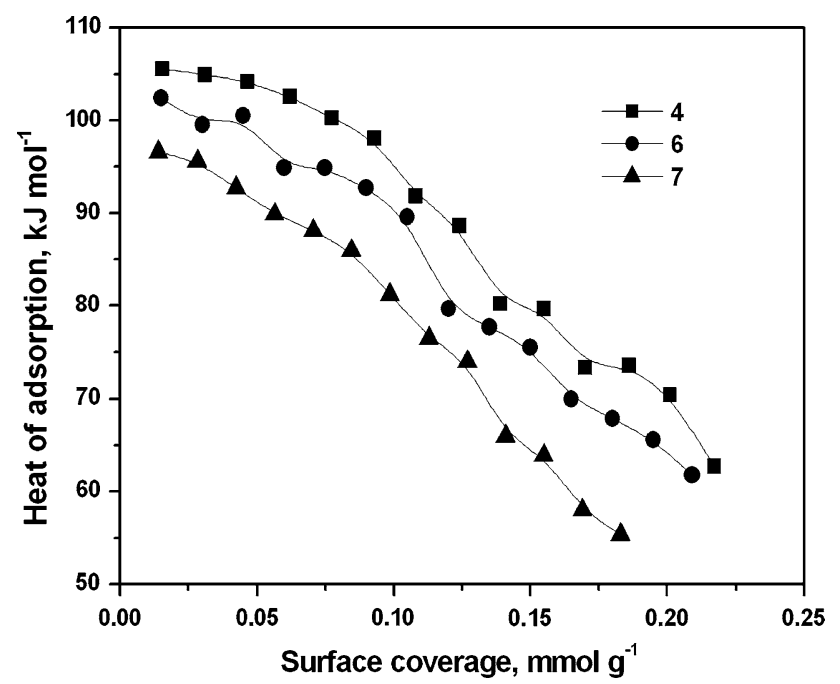

Fig. $4 \mathrm{NH}_{3}$ adsorption microcalorimetry data of sample containing $20 \%$ niobia as a function of calcination temperature. See Table 1 for catalyst details

electronegativity of $\mathrm{Nb}(\mathrm{V})$ compared to $\mathrm{Si}(\mathrm{IV})$ could also cause the formation of Brønsted acid sites by weakening of the $\mathrm{O}-\mathrm{H}$ bond. The strength of acid sites increased with increasing niobia loading up to $20 \mathrm{wt} \%$, and decreased thereafter (Fig. 3). The acid strength decreased at higher calcination temperatures, as expected. Since higher temperatures lead to the formation of niobia particles, as indicated by XRD, we assume that the acid strength is higher when the niobia phase is well dispersed. This agrees with the decreased acid strength of catalyst 5 for which the niobia peaks are better defined, compared to catalyst 4 (Fig. 4).

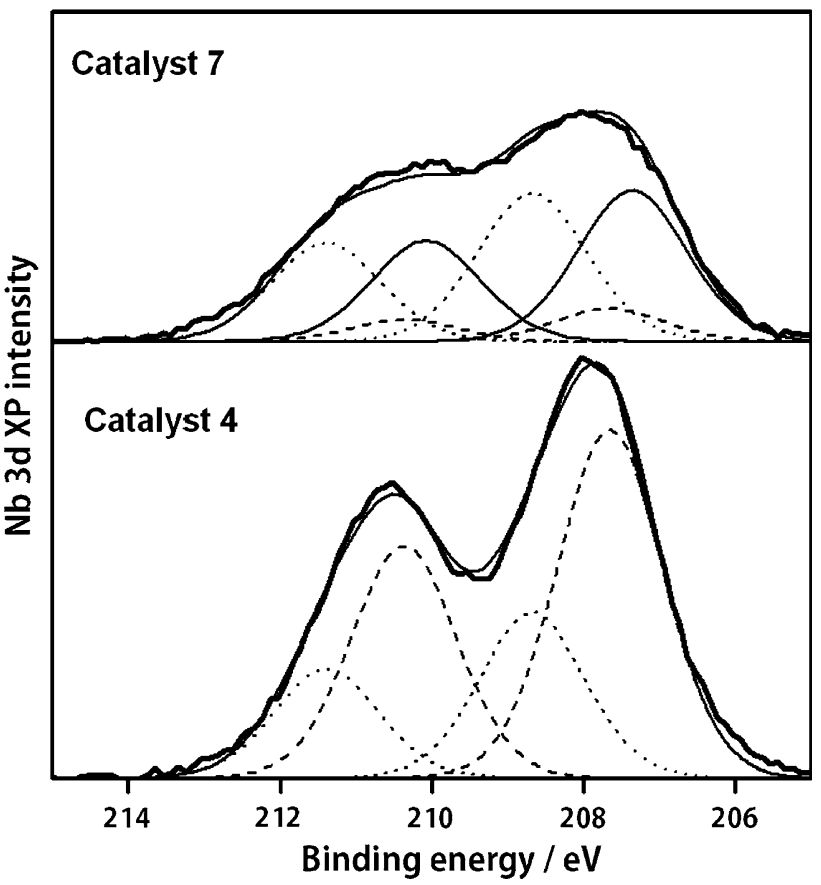

Fig. $5 \mathrm{Nb} 3 \mathrm{~d} \mathrm{X}$-ray photoelectron spectra of the sample containing $20 \% \mathrm{Nb}_{2} \mathrm{O}_{5}$

Samples were analysed by XPS, probing surface composition and $\mathrm{Nb}$ oxidation state. Representative $\mathrm{Nb} 3 \mathrm{~d} X \mathrm{XP}$ spectra are shown in Fig. 5 for the sample containing 20\% $\mathrm{Nb}_{2} \mathrm{O}_{5}$ calcined at $400{ }^{\circ} \mathrm{C}$ (catalyst 4). We see a broad set of spin/orbit split doublets for the $3 \mathrm{~d} 5 / 2$ and $3 \mathrm{~d} 3 / 2$ states at 207.9 and $210.5 \mathrm{eV}$. The $3 \mathrm{~d} 5 / 2$ state can be deconvoluted into two components, with binding energies of 207.7 and $208.7 \mathrm{eV}$, respectively, in good agreement with the presence of $\mathrm{Nb}^{5+}$, with the $3 \mathrm{~d} 5 / 2$ for $\mathrm{Nb}_{2} \mathrm{O}_{5}$ expected at $207.6 \mathrm{eV}$ [25]. The high binding energy component at $208.7 \mathrm{eV}$ may reflect perturbation of the $\mathrm{Nb}_{2} \mathrm{O}_{5}$ which is in direct contact with the support, i.e. at the interface. Such broadening effects were observed previously for $\mathrm{Mo}-\mathrm{Nb}_{2} \mathrm{O}_{5} / \mathrm{SiO}_{2}$ catalysts [28]. Following calcination at $800{ }^{\circ} \mathrm{C}$ (catalyst 7) there is a reduction in the $\mathrm{Nb} 3 \mathrm{~d}$ intensity of the $207.6 \mathrm{eV}$ component and further broadening of the doublet with a new lower binding energy state at $207.4 \mathrm{eV}$ evolving. $\mathrm{Nb}, \mathrm{NbO}$ and $\mathrm{NbO}_{2}$ are expected at 202.2, 203.7 and $205.7 \mathrm{eV}$ respectively, so it is unlikely that this new low binding energy state pertains to reduction of $\mathrm{Nb}_{2} \mathrm{O}_{5}$. We think that high-temperature calcination causes sintering of the $\mathrm{Nb}_{2} \mathrm{O}_{5}$ crystallites, thus shifting the binding energy. The contribution from the interfacial $\mathrm{Nb}_{2} \mathrm{O}_{5}$ remains unchanged, suggesting that it is stable. The surface compositions of the materials determined from XPS show a slight decrease in the $\mathrm{Nb} / \mathrm{Si}$ atomic ratio from 0.04 to 0.03 . This could be due to $\mathrm{Nb}$ loss or $\mathrm{Nb}$ dissolution into the silica matrix during calcination. 


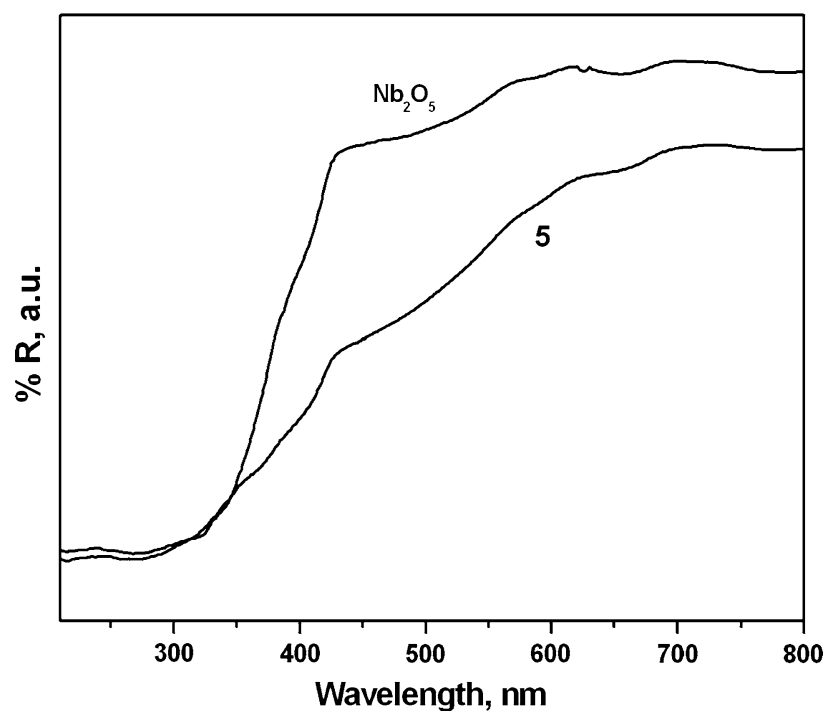

Fig. 6 UV-Vis DRS spectra of bulk niobia and catalyst 5

The oxidation state of $\mathrm{Nb}$ was further confirmed by UVVis DRS spectroscopy (Fig. 6). The spectra are dominated by intense bands corresponding to ligand-to-metal chargetransfer transitions (LMCT from $\mathrm{O}^{2-}$ to $\mathrm{Nb}^{5+}$ ). However, the type of coordination, that is, tetrahedral $(230 \mathrm{~nm})$ or octahedral $\mathrm{Nb}$ species $(\approx 250 \mathrm{~nm})$, could not be distinguished from these broad bands.

\subsection{Catalyst Testing}

We tested the catalysts for the dehydration of glycerol in a gas-phase fixed bed down-flow reactor. The results show that silica-supported niobia catalysts are active for the catalytic dehydration of glycerol. Catalysts exhibited very high initial glycerol conversions, and almost $100 \%$ conversion was obtained with catalyst 4 after $2 \mathrm{~h}$. The major product was acrolein. With silica support alone, very low conversion of glycerol and poor selectivity to acrolein was observed. This indicates that the acidic sites generated by the supported niobia are the actual active species. The byproducts produced during the reaction were 1-hydroxyacetone, acetone, acetaldehyde, allyl alcohol, propionaldehyde and acetic acid, all of which were formed with low selectivities. A number of other byproducts which remain unidentified also were produced in very minor amounts $(<2 \%)$.

The glycerol conversion increases with niobia loading, reaching a maximum at $20 \%$ (Fig. 7 a). The selectivity to acrolein also follows the same trend (Fig. 7b). Note that calcination at higher temperatures such as $800{ }^{\circ} \mathrm{C}$ decreased both glycerol conversion and selectivity to acrolein (Fig. 8).

Comparing these activity results with the acid properties of catalysts evaluated by ammonia adsorption microcalorimetry (Figs. 3, 4) brings out the relation between the acid strength and the acrolein yield. Higher acidic strength is favourable for a higher acrolein yield for this set of catalysts. This can be better understood by Fig. 9, in which heat of adsorption and acrolein formation rate are plotted together. The mass-specific catalytic rates were obtained by normalizing the glycerol consumption and acrolein formation data according to the weight of each catalyst. As can be seen from the figure, these rates were linearly related with the heat of adsorption of ammonia which means that higher acidic strength favours higher yield of acrolein for this set of catalysts.

Though the initial conversions were very high, for all catalysts, conversion of glycerol decreased rapidly with time-on-stream (TOS) as can be observed from Fig. 7, indicating a fast deactivation. However, there was no significant change in the selectivity pattern with TOS and
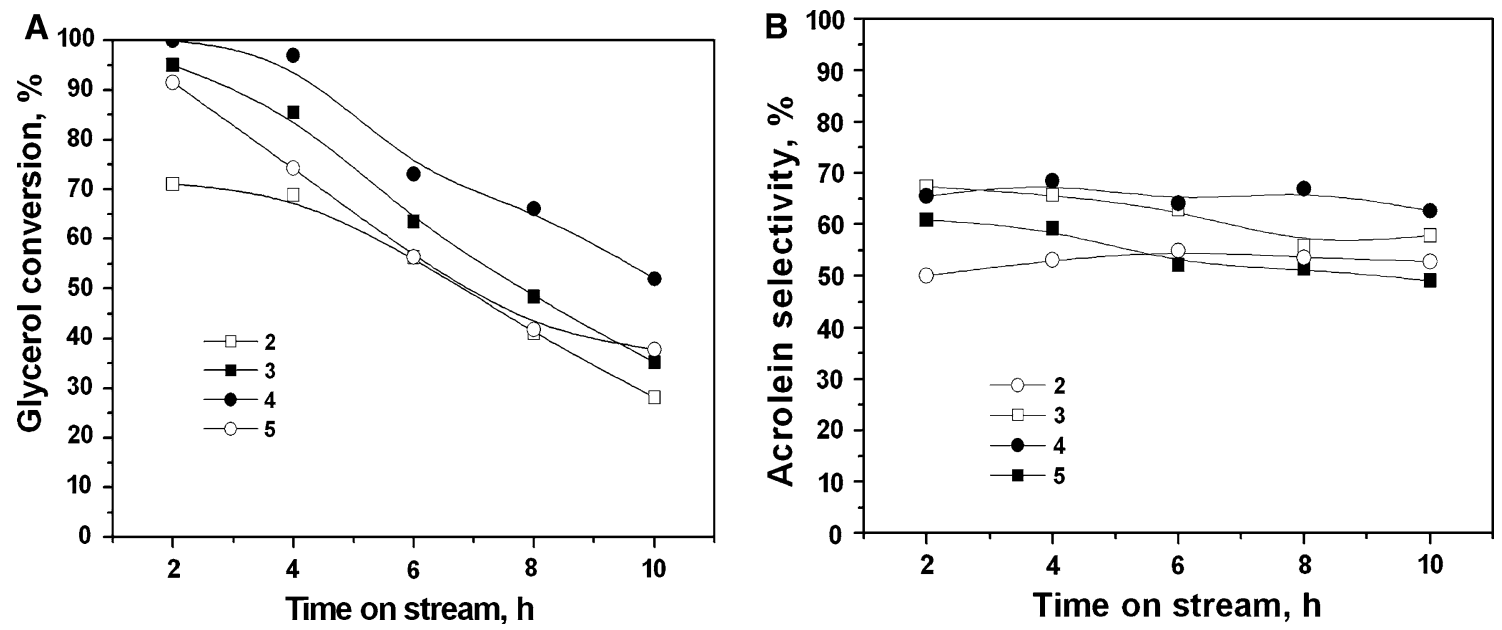

Fig. 7 Glycerol conversion (a) and acrolein selectivity (b) as a function of time on stream for catalysts with different niobia loading. Reaction Temperature: $320{ }^{\circ} \mathrm{C}$, WHSV $=80 \mathrm{~h}^{-1}$ and feed $=30 \%$ solution of glycerol in water. See Table 1 for catalyst details 


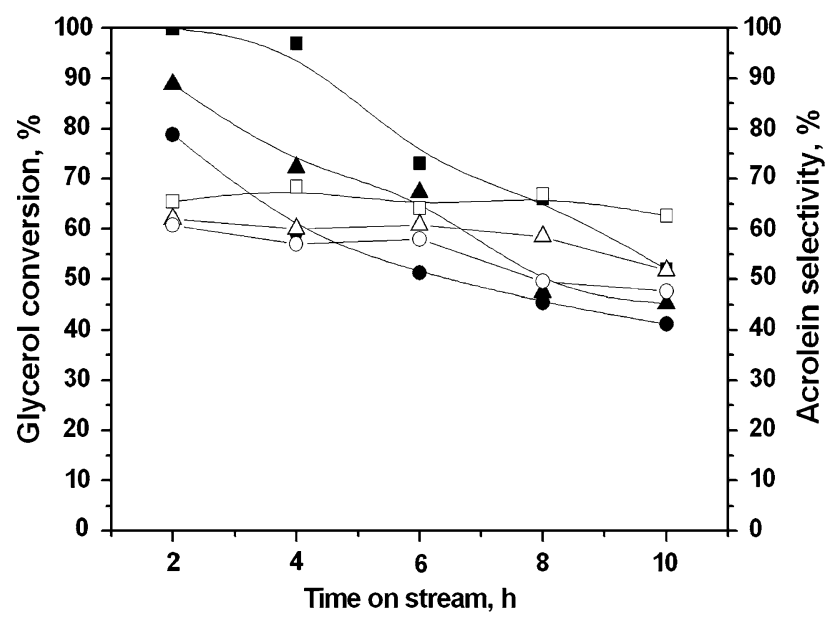

Fig. 8 Glycerol conversion and acrolein selectivity as a function of time on stream for $20 \mathrm{Nb}_{2} \mathrm{O}_{5}-\mathrm{SiO}_{2}$ calcined at $400{ }^{\circ} \mathrm{C}$ (filled square, open square), $600{ }^{\circ} \mathrm{C}$ (filled triangle, open triangle) and $800^{\circ} \mathrm{C}$ (filled circle, open circle). Solid symbols indicate glycerol conversion and open symbols indicate acrolein selectivity. Reaction Temperature: $320{ }^{\circ} \mathrm{C}$, WHSV $=80 \mathrm{~h}^{-1}$ and feed $=30 \%$ solution of glycerol in water

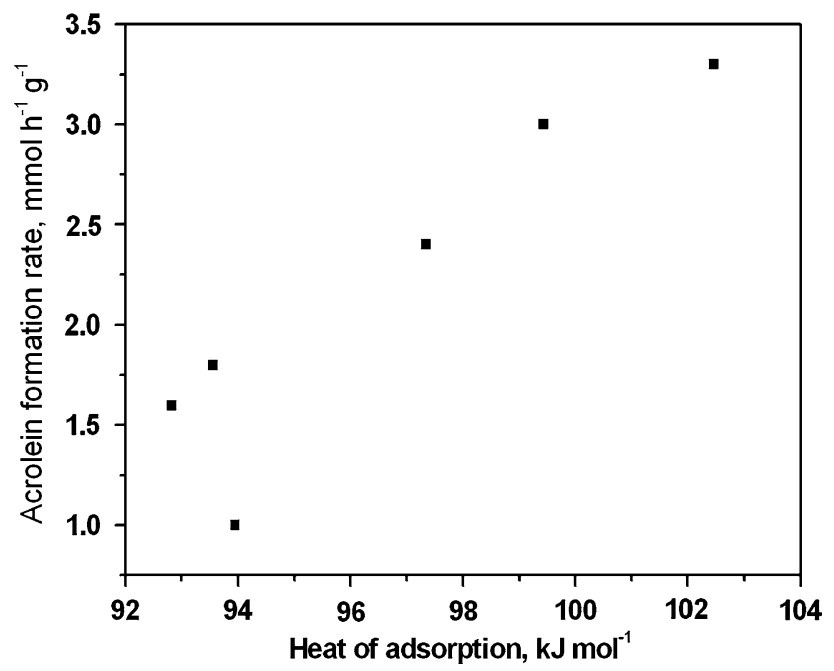

Fig. 9 Relationship between acrolein formation rate (obtained at time on stream $=9-10 \mathrm{~h}$ ) and heat of adsorption for silica-supported niobia catalysts

acrolein was the major product. Since the catalysts are expected to possess water tolerant properties, the most probable reason for the deactivation is coking. To confirm this, the catalysts were removed after reaction and were analysed by $\mathrm{TG}$ in $\mathrm{N}_{2}$ flow. There was a weight loss on the TG curve between 350 and $650{ }^{\circ} \mathrm{C}$ due to burn off of the carbon deposits (Fig. 10). This indicates that the deactivation is indeed mainly due to the coking. The fact that catalysts deactivate in spite of the presence of a large amount of steam during the reaction emphasizes high probability of the side reactions leading to the formation of

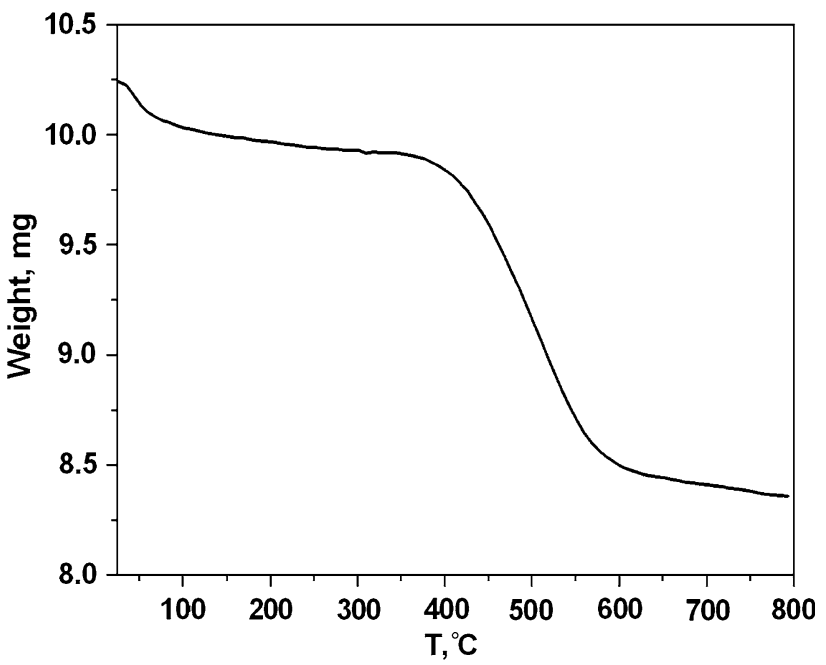

Fig. 10 TG analysis in $\mathrm{N}_{2}$ flow of the catalyst 4 removed after reaction

carbonaceous products. Water tolerance is not sufficient to avoid the deactivation and acid properties need to be fine tuned for this purpose. Nonetheless, the catalysts could be fully regenerated by recalcination of the used catalyst at around $500{ }^{\circ} \mathrm{C}$ for $5 \mathrm{~h}$ in flowing air $\left(30 \mathrm{~mL} \mathrm{~min}{ }^{-1}\right)$.

\section{Conclusions}

Silica-supported niobia catalysts showed significant activity in the catalytic dehydration of glycerol to acrolein in the presence of water. The conversion of glycerol and selectivity to acrolein depends on the niobia loading and calcination temperature. The total acidity was changed depending on the niobia loading and calcination temperature of the catalysts. Catalyst performance was strongly influenced by the total acidity. Deactivation due to carbon deposition was observed for all the catalysts, but an oxidative treatment in air at temperatures around $500{ }^{\circ} \mathrm{C}$ sufficed to recover both acidity and activity.

Open Access This article is distributed under the terms of the Creative Commons Attribution Noncommercial License which permits any noncommercial use, distribution, and reproduction in any medium, provided the original author(s) and source are credited.

\section{References}

1. Statistics of European Biodiesel Board. http://www.ebb-eu.org/ stats

2. Official Journal of the European Union, L140/6, 05-06-2009

3. Corma A, Huber GW, Sauvanaud L, O'Connor P (2008) J Catal 257:163

4. Haas T, Arntz D, Klenk H, Girke W (1994) Pat. EP. 19,930,116,792 
5. Dubois J-L, Duquenne C, Hölderich W, Kervenal J (2006) Pat. WO 2006/087084 A2

6. Tsukuda E, Sato S, Takahashi R, Sodesawa T (2007) Catal Commun 8:1349

7. Chai S, Wang H, Liang Y, Xu B (2007) Green Chem 9:1130

8. Atia H, Ambruster U, Martin A (2008) J Catal 258:71

9. Suprun W, Lutecki M, Haber T, Papp H (2009) J Mol Catal A 309:71

10. Zhou C, Beltramini JN, Fana Y, Lu GQ (2008) Chem Soc Rev 37:527

11. Jerome F, Pouilloux Y, Barrault J (2008) ChemSusChem 1:586

12. Chai S, Wang H, Liang Y, Xu B (2007) J Catal 250:342

13. Wang F, Dubois J, Ueda W (2009) J Catal 268:260

14. Chai S, Wang H, Liang Y, Xu B (2009) Appl Catal A 353:213

15. Peterson TH, Holladay JE, Zacher AH, Gray MJ, Werpy TA, White JF (2009) US20090054694

16. Peterson TH, Zacher AH, Gray MJ, White JF, Holladay JE, Werpy TA (2009) US20090054538

17. Ott L, Bicker M, Vogel H (2006) Green Chem 8:214
18. Ramayya S, Brittain A, DeAlmeida C, Mok W, Antal MJ (1987) Fuel 66:1364

19. Watanabe M, Iida T, Aizawa Y, Aida TM, Inomata H (2007) Bioresour Technol 98:1285

20. Gordillo A, Durán Pachón L, de Jesus E, Rothenberg G (2009) Adv Synth Catal 351:325-330

21. Kiss AA, Dimian AC, Rothenberg G (2006) Adv Synth Catal 348:75

22. Ziolek M (2003) Catal Today 78:47

23. Tanabe K, Okazaki S (1995) Appl Catal A 133:191

24. Shiju NR, AnilKumar M, Hoelderich WF, Brown DR (2009) J Phys Chem C 113:7735

25. Shiju NR, Williams HM, Brown DR (2009) Appl Catal B 90:451

26. Nowak I, Ziolek M (1999) Chem Rev 99:3603

27. Shiju NR, Anilkumar M, Mirajkar SP, Gopinath CS, Rao BS, Satyanarayana CV (2005) J Catal 230:484

28. Damyanova S, Dimitrov L, Petrov L, Grange P (2003) Appl Surf Sci 214:68 